Article

\title{
Biospeckle Optical Coherence Tomography (bOCT) in the Speedy Assessment of the Responses of the Seeds of Raphanus sativus L. (Kaiware Daikon) to Acid Mine Drainage (AMD)
}

\author{
Danyang Li ${ }^{1} \mathbb{D}$, Uma Maheswari Rajagopalan ${ }^{2}$, Y. Sanath K. De Silva ${ }^{1,3} \mathbb{D}^{\text {, Fenwu Liu }}{ }^{4}$ and Hirofumi Kadono ${ }^{1, *}$ \\ 1 Graduate School of Science and Engineering, Saitama University, 255 Shimo-Okubo, Sakura-ku, \\ Saitama 338-8570, Japan; ldanyang05@gmail.com (D.L.); sanath37@gmail.com (Y.S.K.D.S.) \\ 2 Department of Mechanical Engineering, Shibaura Institute of Technology, 3-7-5 Toyosu, Koto Ku, \\ Tokyo 135-8548, Japan; uma@shibaura-it.ac.jp \\ 3 Department of Mechanical and Manufacturing Engineering, Faculty of Engineering, University of Ruhuna, \\ Hapugala, Galle 80000, Sri Lanka \\ 4 Environmental Engineering Laboratory, College of Resource and Environment, \\ Shanxi Agricultural University, Jinzhong 030801, China; liufenwu@sxau.edu.cn \\ * Correspondence: kadono@mail.saitama-u.ac.jp
}

check for updates

Citation: Li, D.; Rajagopalan, U.M.; De Silva, Y.S.K.; Liu, F.; Kadono, H. Biospeckle Optical Coherence

Tomography (bOCT) in the Speedy Assessment of the Responses of the Seeds of Raphanus sativus L. (Kaiware Daikon) to Acid Mine Drainage (AMD). Appl. Sci. 2022, 12, 355. https://doi.org/10.3390/ app12010355

Academic Editors: Kijoon Lee, Adriano Carnevali, Vincenzo Scorcia and Giuseppe Giannaccare

Received: 31 October 2021

Accepted: 27 December 2021

Published: 30 December 2021

Publisher's Note: MDPI stays neutral with regard to jurisdictional claims in published maps and institutional affiliations.

Copyright: (C) 2021 by the authors. Licensee MDPI, Basel, Switzerland. This article is an open access article distributed under the terms and conditions of the Creative Commons Attribution (CC BY) license (https:// creativecommons.org/licenses/by/ $4.0 /)$

\begin{abstract}
The extraction of mineral resources from mines plays a vital role in global socio-economic development. However, acid mine drainage (AMD) has been one of the major pollutants, and a vast area of the agricultural fields has been polluted. Therefore, techniques for monitoring the response of plants to AMD that arise during mineral extraction are necessary. In addition, such a technique becomes especially valuable to understand how the plants could play a role in the phytoremediation of AMD. We propose the use of biospeckle Optical Coherence Tomography (bOCT) to investigate the response of Kaiware daikon seeds under the exposure to simulated AMD at two different concentrations of $40 \mathrm{~mL} / \mathrm{L}$ and $80 \mathrm{~mL} / \mathrm{L}$. OCT images of the Kaiware daikon seed were obtained at a speed of 10 frames per second ( 1 frame: $512 \times 2048$ pixels) for a few tens of seconds For each pixel of the OCT structural images, the contrast across the temporal axis was calculated to give biospeckle contrast OCT images (bOCT images). It was found that bOCT images clearly distinguished the changes due to $40 \mathrm{~mL} / \mathrm{L}$ and $80 \mathrm{~mL} / \mathrm{L}$ of AMD treatments from the control within a short time of around an hour, compared to the conventional OCT images that failed to show any changes. This variation was found to be statistically significant and could reflect the internal activity of the seeds. The proposed bOCT method could be a rapid, non-invasive technique for screening suitable plants in AMD phytoremediation applications.
\end{abstract}

Keywords: biological activities; biospeckle; OCT; acid mine drainage; remediation

\section{Introduction}

Mineral resources are an indispensable primary raw material for social and economic development. However, mining inevitably causes damage to the environment and brings many adverse effects on the ecological environment and human health [1]. When mining mineral resources such as coal and metals, a large amount of mine wastewater is generated due to the oxidation of sulfide minerals contained in the minerals [2]. Such mine wastewater has the characteristics of low $\mathrm{pH}(2-3)$, high level of Fe ions, and high $\mathrm{SO}_{4}{ }^{2-}$, thus, it is called acid mine drainage (AMD) [3]. The infiltration of AMD into the soil could cause soil acidification, resulting in vegetation wither, even causing death.

Furthermore, AMD discharged into rivers will cause the $\mathrm{pH}$ of the water body to decrease rapidly, leading to the death of aquatic organisms and weakening the self-purification ability of the water body [4,5]. AMD is one of the most severe problems for the global 
mining industry. Due to the large output, the long-time span of formation, and the scattered production sources, the AMD problem has attracted widespread attention from mine environmental remediators worldwide.

There are physical methods for AMD remediation, including ion exchange, adsorption, and membrane technology [6]. Chemical methods [7,8] include acid-base neutralization, chemical precipitation, and an electrochemical process. Biological methods [9] include phytoremediation and microbiological methods. Phytoremediation, where certain plants are grown to remediate the contaminated soil, is attracting researchers because of its low cost and non-generation of secondary pollution [10]. Traditional chemical monitoring methods usually employs enzyme activity and metabolite analyses in selecting remediation plants. However, these methods require a lot of monitoring time and are invasive, and thus, are not conducive to dynamic monitoring of different stages of the same sample. Therefore, there is a need to develop techniques that can monitor the effects of AMD speedily and non-invasively.

Optical coherence tomography (OCT) has the advantage of non-invasively detecting the internal structure of biological samples with a few-microns-level resolution, and the technique allows the mapping of 2D or 3D in vivo depth-resolved tomographic images of internal tissue structures [11]. OCT is now widely used in biomedical research [12,13] and is primarily applied in ophthalmology [14]. Several studies on plants using OCT have been published. For example, microstructural changes in rice leaves at different $\mathrm{pH}$ levels [15], monitoring of in vivo growth of pepper seeds treated with different $\mathrm{NaCl}$ concentrations [16], root growth in soil [15], assessment of apple initial bitter rot process [17], screening of melon seeds for diseases [18], and cucumber green mottle mosaic virus (CGMMV) infestation of cucumber seeds [19]. In addition, there are applications for portable OCT [20]. In particular, our group has developed biospeckle OCT (biospeckle optical coherence tomography), or bOCT, and demonstrated the potential of bOCT in the visualization of the response of plant leaves under ozone exposure [21,22], biological activities in pea seed germination [23], the phenotyping of increasing Zn concentrations on seed [24], and speedy visualization of application of phytohormone on plant leaves [25]. Therefore, in this study, we propose the use of bOCT to monitor the response of plants to AMD. To our knowledge, the application of OCT in the study of AMD response on plants has never been reported before. bOCT can be a sensitive and efficient method, thus paving the way to speedily select remediation plants.

We used Kaiware daikon seeds as the sample for the study. They are popular and widely grown in Japan because of their suitable taste and high nutritional value. Furthermore, it has a reasonable seed size, germinating within two days.

\section{Materials and Methods}

\subsection{Simulated $A M D$ and Plant Materials}

At first, the AMD stock solution was stimulated using $0.744 \mathrm{~g} \mathrm{FeSO}_{4}$ dissolved in $250 \mathrm{~mL}$ distilled water with a $\mathrm{pH}$ value of 2.6. Next, the stock solution was diluted with distilled water to get different concentrations of AMD. We used $40 \mathrm{~mL} / \mathrm{L}$ (40 mL AMD stock solution into $1 \mathrm{~L}$ distilled water, $\mathrm{pH}=3.0)$ and $80 \mathrm{~mL} / \mathrm{L}(80 \mathrm{~mL}$ AMD stock solution into $1 \mathrm{~L}$ distilled water, $\mathrm{pH}=2.7$ ) simulated AMD solutions in the experiments. The iron concentrations in the two AMD treatments were $70 \mathrm{mg} / \mathrm{L}$ and $140 \mathrm{mg} / \mathrm{L}$, respectively, close to the real AMD [3].

Kaiware daikon seeds were purchased from a seed company (Tohoku seed company, Utsunomiya, Japan) and were kept in dry conditions before use. Seeds were exposed to simulated AMD of different concentrations, while seeds exposed to distilled water were used as the control. Six seeds were used for each treatment in the bOCT experiments.

Monitoring of the seed germination rate was also conducted, and for this purpose, with 30 seeds for each treatment. All the seeds were kept in a growth chamber (SANYO Electric Co., Ltd., Osaka, Japan) under ambient environmental conditions with a temperature of 
$25^{\circ} \mathrm{C}$, a light intensity of $350 \mu \mathrm{mol} \mathrm{m} \mathrm{m}^{-2} \mathrm{~s}^{-1}$, and a humidity of around $60 \%$. Distilled water was used to replenish water loss from evaporation and transpiration every day.

\subsection{Optical Coherent Tomography (OCT) Experimental System}

A schematic diagram of the spectral-domain optical coherence tomography (SD-OCT) is shown in Figure 1. A superluminescent diode (SUPERLUM, SLD-137-HP3-DBUT-SM-PD, Cork, Ireland) with a central wavelength $\lambda_{0}=836.1 \mathrm{~nm}$ and a bandwidth $\Delta \lambda=$ of $55.2 \mathrm{~nm}$, providing a total outpower of $15.6 \mathrm{~mW}$, was used as a light source. The light from the light source was first coupled to the input port of the circulator (AC Photonics, Inc., Santa Clara, CA, USA) and further divided into two beams by a $2 \times 250 / 50$ fiber coupler (TW850R5A2$2 \times 2$ Wideband Fiber Optic Coupler, $850 \pm 100$ nm, THORLABS, Exeter, UK), illuminating the sample seed and the reference mirror, respectively. The reference arm consisted of collimating lens L1, objective lens L4, and mirror M1, and the sample arm consisted of lenses L2, L3 (LSM03-BB-Scan Lens, EFL = 36 mm, THORLABS, Exeter, UK), and Galvano scanning mirrors. Dispersion was compensated by a glass plate placed in front of the reference mirror, followed by offline mathematical compensation following the collection of data. Light from L3 was reflected by mirror M2 to the seed. The power of the light incident on the seed in the sample arm was $2.6 \mathrm{~mW}$, which is below the irradiance damage threshold for seeds. The two-dimensional scanning mirror (Galvano mirror scanners) can scan laterally in the $X$ and $Y$ directions. The sensitivity was measured to be $96 \mathrm{~dB}$ at a depth of $0.24 \mathrm{~mm}$. The sensitivity roll-off was around $7.94 \mathrm{~dB} / \mathrm{mm}$.

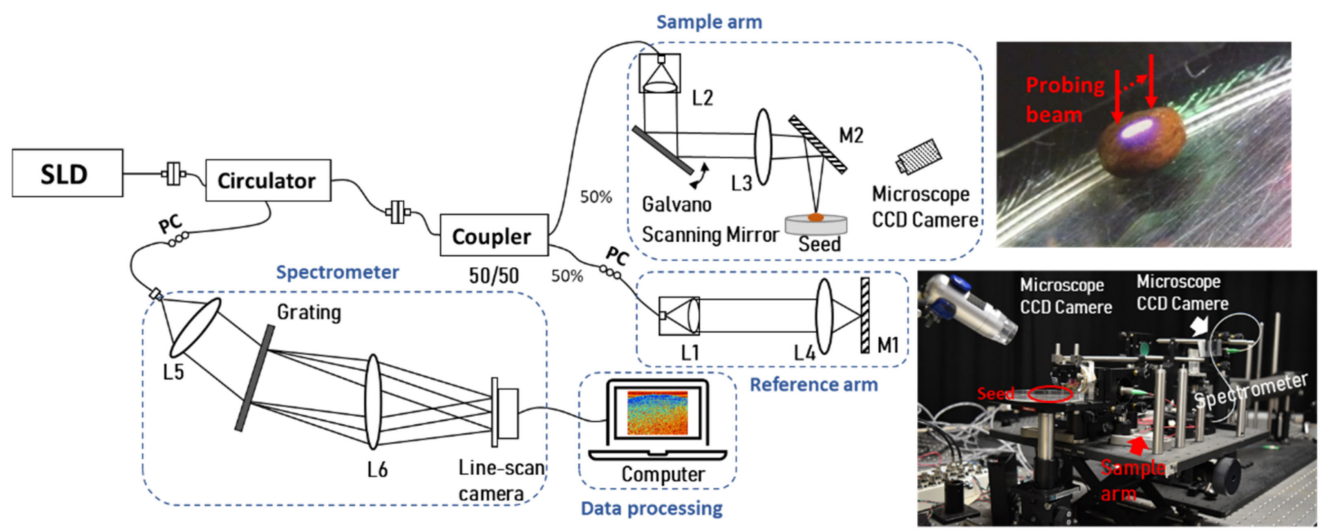

Figure 1. Schematic of Spectral Domain Optical Coherence Tomography (SLD: superluminescent diode, L1 L6: lenses, M1 M2: mirror, PC: polarization controller). Here, the microscope on the sample arm was used to adjust the seed orientation placed on a Petri dish. The photograph shows a picture of the real system, with the encircled region showing the seed. The bright region on the seed indicates the scan line. A cover glass plate was used to partially compensate for the dispersion introduced by the objective lens in the sample arm. Dispersion was also compensated based on offline correction of the data after collection.

Each measurement is a $2048(\mathrm{x})$ and $512(\mathrm{z})$ raster scan over an area of $3.1 \times 1.6 \mathrm{~mm}^{2}$ at an acquisition rate of 10 frames per second (fps). A total of 100 cross-sectional images were recorded. The fiber coupler recombined the backward scattered light from the seed and the reflected light from the reference mirror. This light was directed through a circulator to a spectrometer that consists of a collimator, lens L5, and a grating. The collimated light illuminated the grating to obtain the spectral interference signal focused onto a line scan camera through lens L6. The spectra recorded by the spectrometer were mapped to K-space and then processed with a numerical dispersion compensation algorithm. To acquire the spectral interference signal, a line scan camera (L104k-2k, BASLER, Ahrensburg, Germany) was used, with a total of 2048 pixels.

The depth-resolved reflectivity profile of the sample was obtained by Fourier transforming the spectral interference signal. The acquired OCT structure images were analyzed 
to calculate the contrast of the biospeckle. The depth resolution (axial resolution) of the system in free space was calculated as $6 \mu \mathrm{m}$ using the following Equation (1), and the lateral resolution was calculated as $22 \mu \mathrm{m}$ by Equation (2);

$$
\begin{gathered}
\Delta z=\frac{2 \ln \lambda_{0}^{2}}{\pi n \Delta \lambda}, \\
\Delta x=\frac{4 \lambda_{0}}{\pi}\left[\frac{f}{d}\right],
\end{gathered}
$$

where $f$ is the focal length, $d$ is the beam diameter, and $n$ is the reflectivity index $(n=1.4)$.

Before the OCT measurement, the seeds were dried with paper towels to avoid moisture on the seeds from affecting the data. To ensure that OCT images of all of the seeds were acquired from the same position, the seeds were needed to be adjusted and fixed in position and orientation before scanning. To achieve that, the cotyledon surface was set to be perpendicular to the laser beam, and the center of the cotyledon was irradiated. The embryonic axis was oriented so that it was parallel to the surface of the scan lens. Six seeds used for each AMD treatment were scanned successively and replicated three times. A photo of the system with a typical seed used under the scan is shown in Figure 1.

\subsection{Biospeckle Contrast}

When a biological object is exposed to coherent light such as laser, the light is scattered on the object, and random interference between the scattered light produces a phenomenon called biospeckle [26]. It is suggested that the dynamic behavior results from the moving scatterers [27]. The intensity of the speckle pattern temporally remains constant for a static object. However, the dynamic changes of scattering centers caused by movement in biological objects, such as cytoplasmic flow, organelle movement, cell growth, cell division, and biochemical reactions, result in dynamic speckle patterns called biospeckles. The use of biospeckles in monitoring the biological activities have been reported; for example, monitoring apple fruit development prior to harvesting [28], activity assessment of bacterial and parasitic organisms [29], and identification of water activity change in carrots [30].

The OCT images obtained contain speckles arising out of the movement of the scatterers within the seed tissue. Such resultant speckle pattern changes dynamically. The bOCT image is obtained by calculating the biospeckle contrast $\gamma$ that is defined as the ratio of the standard deviation to the mean value of the biospeckle signal at each pixel along the temporal axis obtained from the successive OCT images with an acquisition interval of $\Delta t$, and is given by,

$$
\begin{gathered}
\gamma(x, y)=\frac{1}{<I_{O C T}(x, y)>}\left[\frac{1}{N} \sum_{j=1}^{N}\left\{I_{O C T}(x, y ; j)-<I_{O C T}(x, y)>\right\}^{2}\right]^{\frac{1}{2}} \\
<I_{O C T}(x, y)>=\frac{1}{N} \sum_{j=1}^{N} I_{O C T}(x, y ; j)
\end{gathered}
$$

where $x, y$ represents the pixel coordinates, $j$ is the frame number, $N$ indicates the total number of scans, $I_{o c t}(x, y ; j)$ is the intensity at pixels $(x, y)$ of a particular frame $j$ and $<\operatorname{Ioct}(x, y)>$ is the mean of the images obtained over time.

\subsection{Traditional Physiological Indicators}

Indicators, namely, germination rate, weights, and heights were measured at different stages of the seeds, and were used for comparison with the bOCT results.

A total of 30 seeds were used per treatment. The number of germinated seeds in each treatment was counted every $12 \mathrm{~h}$ followed by normalization by the total number to obtain the germination percentage in each period.

Seedlings were collected after seven days of growth in each treatment, washed with distilled water, dried with filter paper, and weighed on an electronic balance with an accuracy of $0.0001 \mathrm{~g}$ to get fresh weight. The plants were then placed in an oven at $105^{\circ} \mathrm{C}$ 
for $15 \mathrm{~min}$ for de-enzyming, and then the temperature was adjusted to $75^{\circ} \mathrm{C}$ to dry to a constant weight. The dry weight of the plants was obtained by weighing with an electronic balance immediately after removing the plants from the oven.

The water content of the plant is a common indicator of the water status of plant tissues. The water content affecting the growth condition of plants has a significant impact on the quality of fruits and vegetables [31] and is defined by the following relation;

Water content $=($ Fresh Weight - Dry Weight $) /$ Fresh weight $\times 100 \%$.

Shoot and root lengths were measured with a ruler of $0.1 \mathrm{~cm}$ accuracy after the seedlings were grown for seven days in each treatment. The root-to-shoot ratio (RS ratio) was calculated by dividing root length by shoot length.

\subsection{Data Analysis}

Biospeckle contrast images were calculated using Matlab 2016, and the significance among treatments were tested using LSD test with SPSS software $(p<0.05)$.

\section{Results}

\subsection{Comparison of OCT Structural Images and bOCT Biospeckle Contrast Images after AMD} Exposure for $1 \mathrm{~h}$

The OCT images of the Kaiware daikon seeds exposed under different AMD concentrations of the control, $40 \mathrm{~mL} / \mathrm{L}$, and $80 \mathrm{~mL} / \mathrm{L}$ AMD after an exposure of $1 \mathrm{~h}$ to AMD are shown in Figure 2a-c with logarithmic intensity scale. Reflectivity signals of the OCT images can visualize the internal laminar structure of the seed. Bright regions correspond to stronger OCT reflectivity signal, while dark regions correspond to reduced reflectivity. At the very top, the seed coat and the epidermis can be seen with greater reflectivity. There is also noise related to strong scattering due to the inhomogeneous nature of the structures within the measurement volume determined by the coherence of the source. The scattered light interferes to produce a granular pattern called biospeckles, that changes with time due to the activity within the seed tissue.
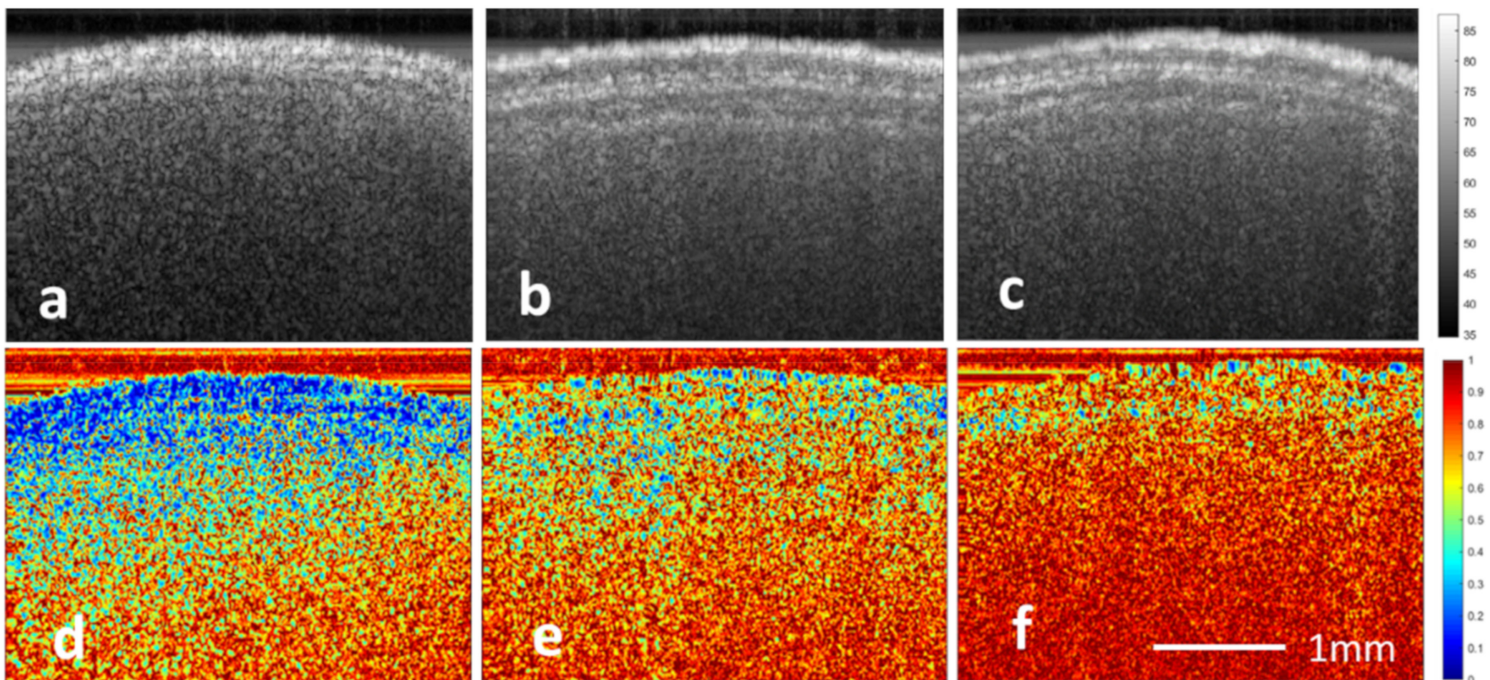

Figure 2. Cross sections of OCT structural (top row) and bOCT (bottom row) images after just an hour of AMD exposure for $(\mathbf{a}, \mathbf{d}) 0 \mathrm{~mL} / \mathrm{L}$ or the control, $(\mathbf{b}, \mathbf{e}) 40 \mathrm{~mL} / \mathrm{L}$ and $(\mathbf{c}, \mathbf{f}) 80 \mathrm{~mL} / \mathrm{L}$.

From a series of OCT frames acquired in a few seconds, the bOCT images were calculated across the acquisition period under each of the conditions, namely, the control, $40 \mathrm{~mL} / \mathrm{L}$ AMD, and $80 \mathrm{~mL} / \mathrm{L}$ AMD, and are, respectively, shown in Figure $2 \mathrm{~d}-\mathrm{f}$. As can be seen in Figure $2 \mathrm{a}-\mathrm{c}$, there are no differences seen in the structural images with the change of AMD concentrations. On the other hand, comparing the biospeckle images obtained under 
different conditions, a clear difference could be seen. In the bOCT images, red regions correspond to higher temporal variation while blue regions correspond to lower temporal fluctuation. There are more red regions in the bOCT images for seeds exposed to AMD than those of the control. Moreover, the bOCT image of seed in $80 \mathrm{~mL} / \mathrm{L}$ AMD (Figure 2f) has more red parts than those exposed to $40 \mathrm{~mL} / \mathrm{L}$ AMD (Figure 2e).

\subsection{Comparison of Biospeckle Contrast of Seeds after AMD Exposure for $1 \mathrm{~h}$ and Germination Percentage within $48 \mathrm{~h}$}

The bOCT images can be used to know the trend of changes between different treatments, and further quantitative analysis of the bOCT images can be performed to analyze the significant differences between different treatments. Figure S1 shows the OCT structure images, obtained by averaging 100 OCT (x-z) scans. A total of six specific rectangular localized regions, namely the regions of interest (ROIs), were selected in the region close to the seed coat and from the slightly deeper region. The depth of the selected ROIs is within $240 \mu \mathrm{m}$ below seed surface; the choice of ROIs is well within the sensitivity limits of the system. The biospeckle contrast of each ROI was obtained by Equation (3) in the method section, and six ROIs were averaged to obtain the average value of the biospeckle contrast of each seed (Figure S1). Next, six seeds were measured for each treatment. A grand average of the biospeckle contrast calculated from six seeds was calculated and is shown in Figure 3.

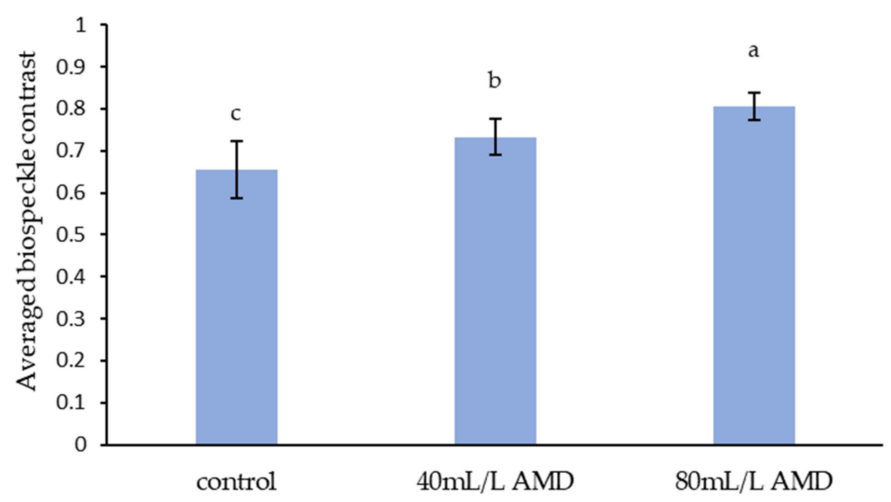

Figure 3. Averaged biospeckle contrast values of 6 seeds under each treatment after an exposure of one hour (different letters, a b c, represent statistical differences between treatments; the error bar represents standard deviation; Fisher-LSD multiple comparison; $p<0.05$ level; number $\mathrm{N}=6$ ).

In the figure, the biospeckle contrast values of the seeds under different treatments showed significant differences: $80 \mathrm{~mL} / \mathrm{L}>40 \mathrm{~mL} / \mathrm{L}>$ control. The results indicate that the activity of the seeds was significantly different from that of the control after $1 \mathrm{~h}$ of AMD treatment, and the contrast of the seeds under $80 \mathrm{~mL} / \mathrm{L}$ AMD treatment was significantly higher than that under $40 \mathrm{~mL} / \mathrm{L}$ AMD. Next, we compared the contrast with the germination rate.

The germination could be affected by many factors such as humidity and light levels. The structure of the seed changes dynamically during germination, and this is dependent on the $\mathrm{pH}$ of the medium used for germination. Environmental stress or stimulation, such as the presence of AMD, can affect the metabolic rate, organelle morphology, and locomotion rate of seeds and plants [32]. AMD has the effect of changing the $\mathrm{pH}$ of the medium and, thus, becomes an environmental stress, introducing physiological changes during seed germination. We expect such physiological changes would lead to changes in scatterers or organelles within the seed. This, in turn, would lead to changes in the intensity of the random interference pattern or a change in biospeckles. Thus, the changes observed under different AMD treatments could be hypothesized to be related to the biological activity of the seed. Moreover, depending on different time points, namely one hour and also at $48 \mathrm{~h}$, the effects due to AMD could be different. 
It is well known that seed vigor is proportional to germination speed $[33,34]$. To test the hypothesis, we monitored the percentage of germination of seeds within $48 \mathrm{~h}$ (Figure 4 ). As shown in Figure 4, the germination percentage of seeds treated with $40 \mathrm{~mL} / \mathrm{L}$ and $80 \mathrm{~mL} / \mathrm{L}$ AMD was higher than that of the control within $36 \mathrm{~h}$, while the germination rate of seeds treated with $80 \mathrm{~mL} / \mathrm{L}$ AMD was the highest. However, at $48 \mathrm{~h}$, the germination percentage of all of the treated seeds reached $100 \%$. The results showed that AMD could improve the germination speed of seeds, and the germination speed of seeds was proportional to the seed vigor. The results may indicate that the seed vigor within $48 \mathrm{~h}$ was $80 \mathrm{~mL} / \mathrm{L}$ AMD > $40 \mathrm{~mL} / \mathrm{L} \mathrm{AMD}>$ control. These results were consistent with the biospeckle contrast comparison trend obtained just $1 \mathrm{~h}$ later, and this confirmed the hypothesis that bOCT could reveal vigor speedily.

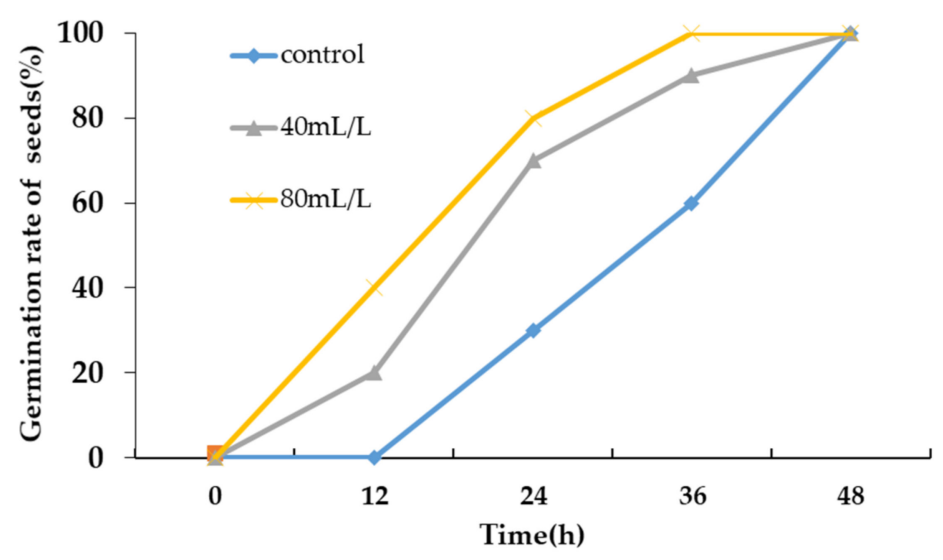

Figure 4. Percentage of seed germination under different treatments.

3.3. Comparison of Biospeckle Contrast of Seeds after AMD Exposure for $48 \mathrm{~h}$ and Biomass after 7 Days

The percentages of seeds germinated at $48 \mathrm{~h}$ under different treatments were the same (Figure 4), and there was no noticeable difference in appearance. Therefore, we decided to investigate if there are differences in the internal activity of seeds at $48 \mathrm{~h}$. The bOCT method was used to monitor the seeds under different treatments, which did not damage the germinated seeds and was beneficial to observe the subsequent growth of seeds.

The OCT images of the Kaiware daikon seeds exposed under different AMD concentrations of the control, $40 \mathrm{~mL} / \mathrm{L}$, and $80 \mathrm{~mL} / \mathrm{L}$ AMD after an exposure of $48 \mathrm{~h}$ to AMD are shown in Figure 5a-c. There were no significant differences seen in the structural images with the change of treatment.

The bOCT images of seeds exposed to different treatments for $48 \mathrm{~h}$ are shown, respectively, in Figure 5d-f. A clear difference could be seen due to different AMD concentrations. The temporal variation is higher in the red regions compared to the blue regions. The blue part was more in the AMD treatment than in the control, indicating that the temporal variations in the AMD treatments were lower than that in the control after $48 \mathrm{~h}$. The temporal change in the $80 \mathrm{~mL} / \mathrm{L}$ AMD treatment was lower than that in the $40 \mathrm{~mL} / \mathrm{L}$ AMD treatment.

Figure 6 is obtained by calculating the averaged biospeckle contrast of six seeds under each treatment. The results showed that there were significant differences between the treatments. The contrasts of seeds under AMD treatments were significantly lower than that of the control, and the biospeckle contrast of seeds exposed to $80 \mathrm{~mL} / \mathrm{L}$ AMD was significantly lower than that under $40 \mathrm{~mL} / \mathrm{L}$ AMD (Figure 6). 

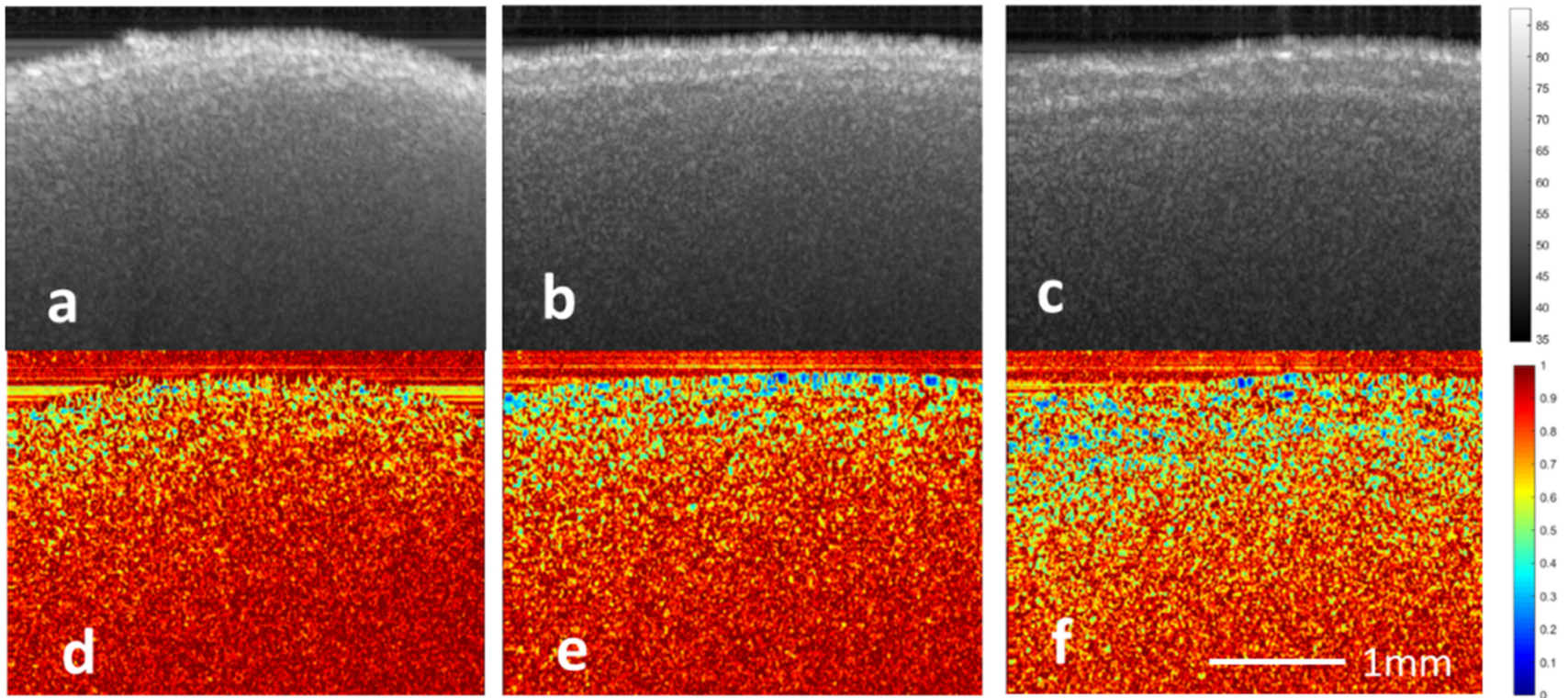

Figure 5. Cross sections of OCT structural (top row) and bOCT (bottom row) images after $48 \mathrm{~h}$ of AMD exposure for $(\mathbf{a}, \mathbf{d}) 0 \mathrm{~mL} / \mathrm{L}$ or the control, $(\mathbf{b}, \mathbf{e}) 40 \mathrm{~mL} / \mathrm{L}$, and $(\mathbf{c}, \mathbf{f}) 80 \mathrm{~mL} / \mathrm{L}$.

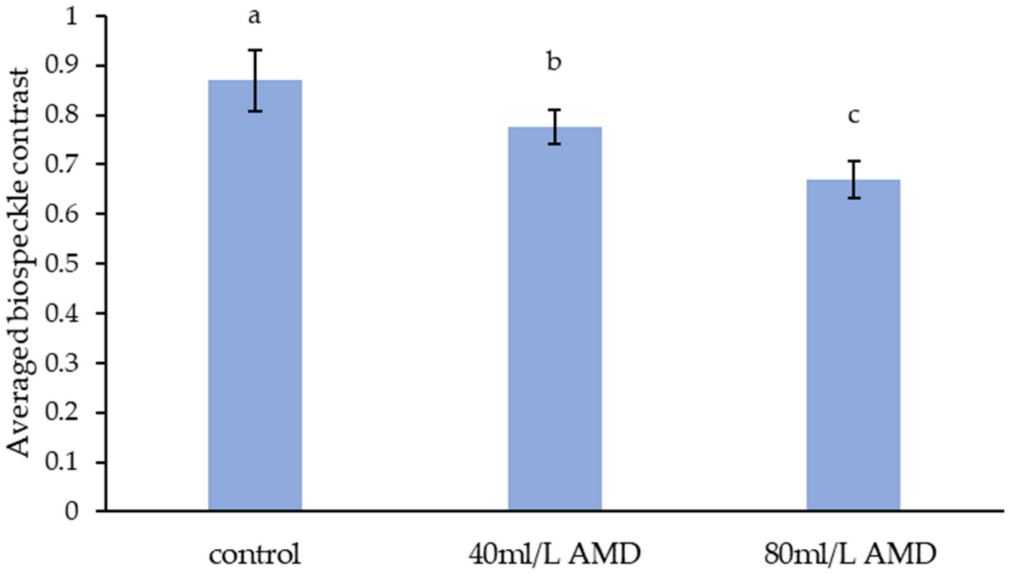

Figure 6. Averaged biospeckle contrast value of seeds under different treatments after $48 \mathrm{~h}$ exposure. (Different letters, a b c, represent statistical differences between treatments; the error bar represents standard deviation; Fisher-LSD multiple comparison; $p<0.05$ level, Number $\mathrm{N}=6$ ).

After 7 days, the biomasses of kaiware daikon under each treatment were measured. Figure 7 shows the photograph of the plants' growth under different treatments after 7 days. Depending on AMD treatment levels, the plants growth was significantly different with clear changes in appearance. At the same time, the shoot length, root length, shoot root ratio (RS ratio), fresh weight, dry weight, and water content of the plant were measured (Figures 8 and 9).

There were significant differences in shoot length between treatments (Figure 8). The difference in root length between the control and $80 \mathrm{~mL} / \mathrm{L}$ AMD treatment was significant but not significant with $40 \mathrm{~mL} / \mathrm{L}$ AMD treatment. There was a significant difference in the ratio of root to shoot between the control and $80 \mathrm{~mL} / \mathrm{L}$ AMD treatment, but the difference with $40 \mathrm{~mL} / \mathrm{L}$ AMD treatment was not significant. These results reveal that AMD inhibits shoot growth, and high concentration AMD inhibits root growth. 


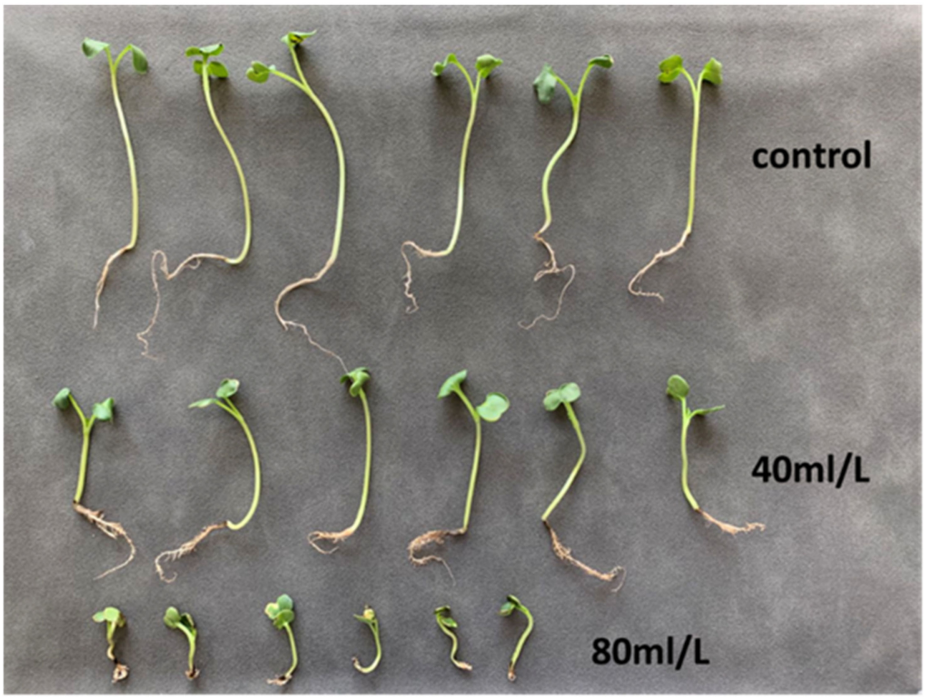

Figure 7. The photo of Kaiware daikon with different treatments after 7 days. A clear difference in the seedlings due to the exposure to AMD can be seen.

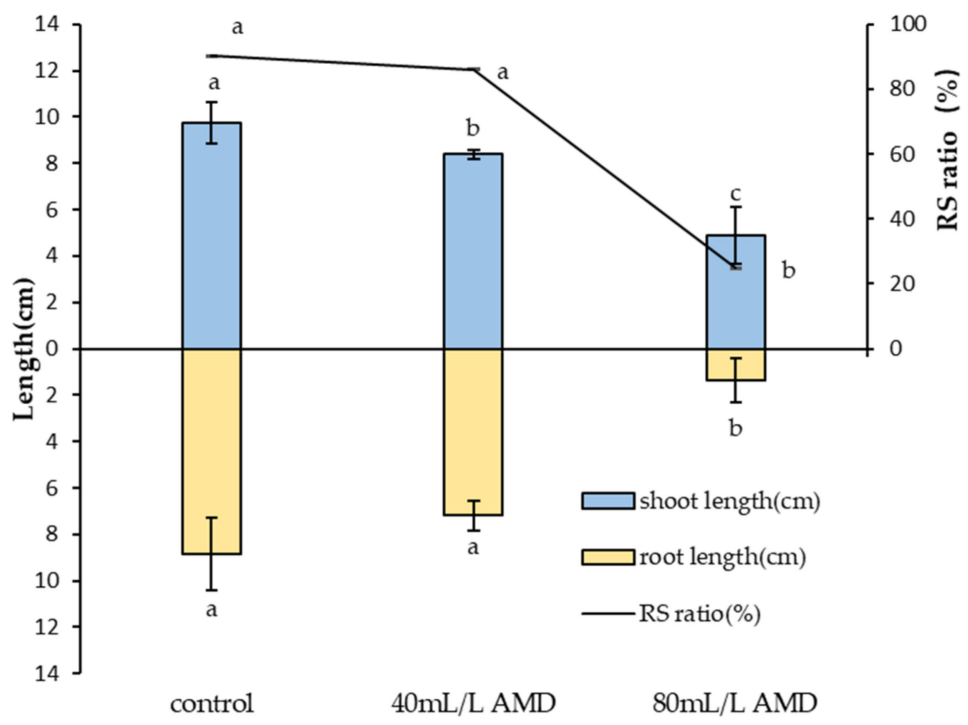

Figure 8. Shoot length, root length, and RS ratio of Kaiware daikon under different treatments (different letters, a b c, represent statistical differences between treatments; the error bar represents standard deviation; Fisher-LSD multiple comparison; $p<0.05$ level; number $\mathrm{N}=6$ ).

The differences in fresh weight between treatments were significant but not in dry weight (Figure 9). The difference between the fresh weight water content of the plants under the control and $80 \mathrm{~mL} / \mathrm{L}$ AMD treatment was significant, and the difference with $40 \mathrm{~mL} / \mathrm{L}$ AMD treatment was not significant. The results indicate that $80 \mathrm{~mL} / \mathrm{L}$ AMD reduces the water content of Kaiware daikon.

The tendency of plant growth after 7 days was consistent with the bOCT results at $48 \mathrm{~h}$, indicating that the bOCT results could reveal internal activity of the seed much in advance. In addition, there were obvious differences in the morphology of the roots under different treatments (Figure 7). The roots of the plants under $80 \mathrm{~mL} / \mathrm{L}$ AMD were very short or almost non-existent. The roots of the plants under $40 \mathrm{~mL} / \mathrm{L}$ AMD had more short branches than the control. 


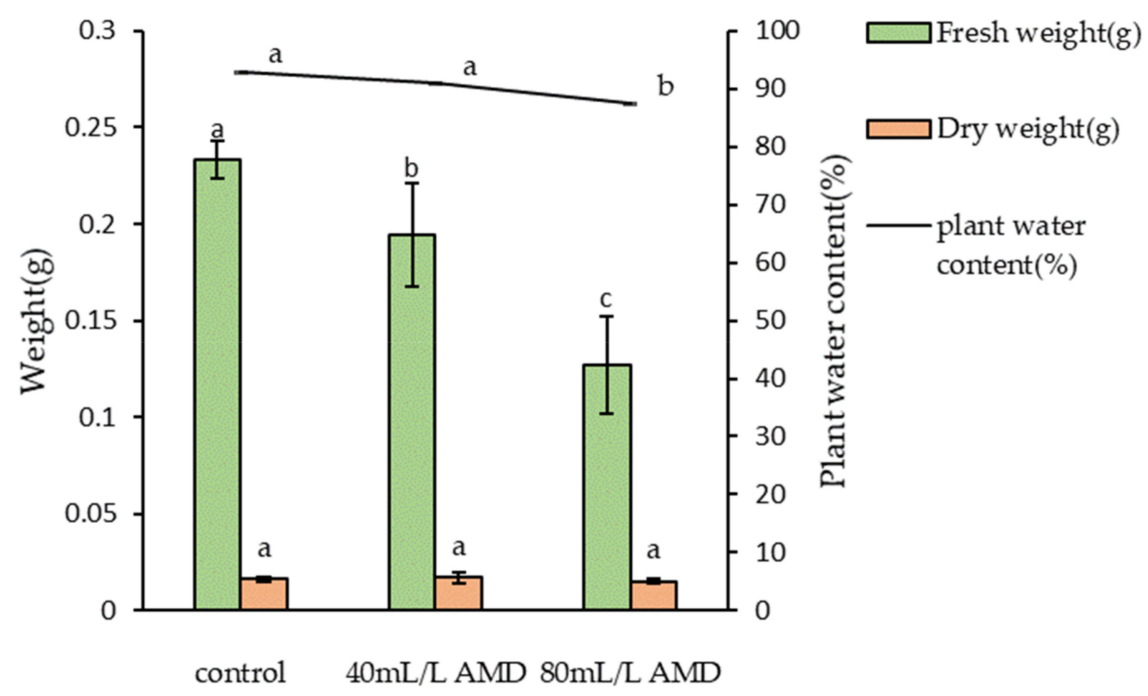

Figure 9. Fresh weight, dry weight, and water content of Kaiware daikon under different treatments (different letters, a b c, represent statistical differences between treatments; the error bar represents standard deviation; Fisher-LSD multiple comparison; $p<0.05$ level; number $\mathrm{N}=6$ ).

\section{Discussion}

The current study investigates the application of biospeckle OCT to monitor the dynamic changes during seed germination and under the presence of AMD. The structure of a seed changes dynamically during germination. Thus, in practice, OCT, a technique that visualizes structures, should be capable of monitoring structural changes. However, because the structural changes are random, generating random changes in OCT intensity, we proposed to use biospeckle OCT for investigating seed germination under AMD.

Furthermore, the germination could be affected by many factors such as humidity, light levels, and environmental stress. AMD, one such environmental stress, can affect the metabolic rate, organelle morphology, and locomotion rate of seeds and plants [32]. During germination, the structure of the seed changed dynamically, and this was dependent on the $\mathrm{pH}$ of the medium used for germination.

AMD has the effect of changing the $\mathrm{pH}$ of the medium and, thus, becomes an environmental stress, introducing physiological changes during seed germination. We expect such physiological changes would lead to changes in scatterers or organelles within the seed.

As possible scatterers, there are several internal microstructures such as mitochondria, Golgi bodies, and possibly chloroplasts within the seed. The movement of such structures from cell growth, cell division, and cytoplasmic flow, could contribute to the slow-to-rapid changes that would lead to changes in the intensity of the random interference patterns; in other words, changes in biospeckles observed in the bOCT images. Therefore, external environmental stress can affect those movements [35-37], leading to the difference in bOCT images of the seeds treated with AMD at different concentrations.

Murata et al. [38] studied the effect of different $\mathrm{pH}$ levels (3.0-6.0) on germination and seedling growth of groundnuts. They found that a low $\mathrm{pH}$ did not affect seed germination but significantly reduced seedling survival and growth. The results on seedling growth are consistent with our findings. However, low-pH AMD accelerated the germination of kaiware seeds in this study. There are two possible reasons: Low $\mathrm{pH}$ accelerates the softening of the hard seed coat of kaiware, allowing water to enter the endosperm more quickly. The water enters and softens the seed coat, and oxygen penetrates more easily, enhancing the embryo's respiration, making it easy for the embryo to break through the seed coat [39]. In addition, other studies have shown that $\mathrm{FeSO}_{4}$ can promote seed germination $[40,41]$.

The elements Fe and $\mathrm{S}$ contained in AMD are essential elements for plants, but the results of bOCT at $48 \mathrm{~h}$ and biomass after 7 days showed that the plants under AMD 
treatment were in poor condition. Islam $\mathrm{A}$ et al. [42] studied the effect of different $\mathrm{pH}$ nutrient solutions on ginger, cassava, maize, wheat, French beans, and tomatoes. The results showed that the damaging effects of low $\mathrm{pH}$ on the root system were observed in all species. At $\mathrm{pH}$ 3.3, roots of all species were shortened, thickened, relatively few in number, turned brown or dark gray in color, and the lateral root growth was severely inhibited. The roots are an essential part of nutrient transport, and poor root growth will affect the growth of shoots. This is consistent with the findings of the present study that the negative effect of AMD on seedlings is higher levels of AMD or lower $\mathrm{pH}$ affecting macro growth. Our studies with bOCT also suggest low $\mathrm{pH}$ can have a significant effect on the earlier stages of germination, thus possibly shortening overall duration requirements for the case of kaiware daikon species.

\section{Conclusions}

Combined with the results of $1-\mathrm{h} \mathrm{bOCT}$ and the percentage of germination within $48 \mathrm{~h}$, it was found that bOCT could observe the change of seed internal activity after only $1 \mathrm{~h}$ when the seeds were under AMD stress.

Combined with the results of 48-h bOCT and plant biomass after 7 days, it was found that bOCT could predict plant growth after 7 days by monitoring the internal activity of seeds after $48 \mathrm{~h}$.

Although the plants used in this experiment are not suitable for AMD remediation, the experimental results can still be used as a reference for selecting remediation plants. The advancement of this new technology is conducive to opening a new era of non-invasive sensitive detection of plant indicators.

Supplementary Materials: The following supporting information can be downloaded at: https:/ / www.mdpi.com/article/10.3390/app12010355/s1, Figure S1: OCT structural image (x-z) scans with six regions of interest (ROI) indicated by rectangles. Each rectangle corresponds to $512 \times 25$ pixels. The average contrast of the ROIs was used to calculate the average across six seed to give the grand average.

Author Contributions: Conceptualization, D.L., F.L. and H.K.; methodology, H.K., U.M.R.; software, H.K.; validation, D.L.; formal analysis, D.L.; investigation, D.L.; resources, D.L.; data curation, D.L.; writing—original draft preparation, D.L.; writing—review and editing, Y.S.K.D.S., U.M.R. and H.K.; visualization, D.L.; supervision, H.K.; project administration, H.K.; funding acquisition, H.K. All authors have read and agreed to the published version of the manuscript.

Funding: This research was funded by the JSPS Grant-in-Aid for Scientific Research (B) 19H04289 of the Ministry of Education, Culture, Sports, Science, and Technology in Japan. And The APC was funded from the above-mentioned grant.

Data Availability Statement: The data presented in this study are available on request from the corresponding author.

Acknowledgments: D.L. would like to express thank for the advice from Y. Lim regarding the OCT system.

Conflicts of Interest: The authors declare no conflict of interest.

\section{References}

1. Simate, G.S.; Ndlovu, S. Acid mine drainage: Challenges and opportunities. J. Environ. Chem. Eng. 2014, 2, 1785-1803. [CrossRef]

2. Akcil, A.; Koldas, S. Acid Mine Drainage (AMD): Causes, treatment and case studies. J. Clean. Prod. 2006, 14, 1139-1145. [CrossRef]

3. Dong, Y.; Liu, F.; Qiao, X.; Zhou, L.; Bi, W. Effects of acid mine drainage on calcareous soil characteristics and Lolium perenne L. germination. Int. J. Environ. Res. Public Health 2018, 15, 2742. [CrossRef] [PubMed]

4. Chamorro, S.; Barata, C.; Piña, B.; Casado, M.; Schwarz, A.; Sáez, K.; Vidal, G. Toxicological analysis of acid mine drainage by water quality and land use bioassays. Mine Water Environ. 2018, 37, 88-97. [CrossRef]

5. Mapanda, F.; Nyamadzawo, G.; Nyamangara, J.; Wuta, M. Effects of discharging acid-mine drainage into evaporation ponds lined with clay on chemical quality of the surrounding soil and water. Phys. Chem. Earth Parts A/B/C 2007, 32, 1366-1375. [CrossRef] 
6. Oyewo, O.A.; Agboola, O.; Onyango, M.S.; Popoola, P.; Bobape, M.F. Current methods for the remediation of acid mine drainage including continuous removal of metals from wastewater and mine dump. In Bio-Geotechnologies for Mine Site Rehabilitation; Elsevier: Amsterdam, The Netherlands, 2018; pp. 103-114.

7. Park, S.-M.; Shin, S.-Y.; Yang, J.-S.; Ji, S.; Baek, K. Selective recovery of dissolved metals from mine drainage using electrochemical reactions. Electrochim. Acta 2015, 181, 248-254. [CrossRef]

8. Rodríguez-Galán, M.; Moreno, F.M.B.; Vázquez, S.; Torralvo, F.A.; Vilches, L.F.; Zhang, Z. Remediation of acid mine drainage. Environ. Chem. Lett. 2019, 17, 1529-1538. [CrossRef]

9. Rambabu, K.; Banat, F.; Pham, Q.M.; Ho, S.-H.; Ren, N.-Q.; Show, P.L. Biological remediation of acid mine drainage: Review of past trends and current outlook. Environ. Sci. Ecotechnology 2020, 2, 100024. [CrossRef]

10. Kiiskila, J.D.; Sarkar, D.; Panja, S.; Sahi, S.V.; Datta, R. Remediation of acid mine drainage-impacted water by vetiver grass (Chrysopogon zizanioides): A multiscale long-term study. Ecol. Eng. 2019, 129, 97-108. [CrossRef]

11. Huang, D.; Swanson, E.A.; Lin, C.P.; Schuman, J.S.; Stinson, W.G.; Chang, W.; Hee, M.R.; Flotte, T.; Gregory, K.; Puliafito, C.A.; et al Optical coherence tomography. Science 1991, 254, 1178-1181. [CrossRef]

12. Kashani, A.H.; Chen, C.-L.; Gahm, J.K.; Zheng, F.; Richter, G.M.; Rosenfeld, P.J.; Shi, Y.; Wang, R. Optical coherence tomography angiography: A comprehensive review of current methods and clinical applications. Prog. Retin. Eye Res. 2017, 60, 66-100. [CrossRef] [PubMed]

13. Kislevitz, M.; Akgul, Y.; Ba, C.W.; Hoopman, J.; Kenkel, J. Use of optical coherence tomography (OCT) in aesthetic skin assessment-A short review. Lasers Surg. Med. 2020, 52, 699-704. [CrossRef] [PubMed]

14. Rebolleda, G.; Diez-Alvarez, L.; Casado, A.; Sánchez-Sánchez, C.; De Dompablo, E.; González-López, J.J.; Muñoz-Negrete, F.J OCT: New perspectives in neuro-ophthalmology. Saudi J. Ophthalmol. 2015, 29, 9-25. [CrossRef] [PubMed]

15. Ekta; Singh, A.K.; Pandey, D.M. Microstructural changes in rice (Oryza sativa L.) leaves under varying low $\mathrm{pH}$ levels: A swept-source optical coherence tomography approach. Laser Phys. 2021, 31, 085601.

16. Ravichandran, N.K.; Wijesinghe, R.E.; Lee, S.-Y.; Shirazi, M.F.; Park, K.; Jung, H.-Y.; Jeon, M.; Kim, J. Swept source optical coherence tomography for in vivo growth monitoring of capsicum annuum seeds treated with different $\mathrm{NaCl}$ concentrations. In Proceedings of the 25th Optical Fiber Sensors Conference (OFS), Jeju, Korea, 24-28 April 2017.

17. Wijesinghe, R.E.; Lee, S.-Y.; Ravichandran, N.K.; Shirazi, M.F.; Kim, P.; Jung, H.-Y.; Jeon, M.; Kim, J. Biophotonic approach for the characterization of initial bitter-rot progression on apple specimens using optical coherence tomography assessments. Sci. Rep. 2018, 8, 1-10.

18. Lee, C.; Lee, S.-Y.; Kim, J.-Y.; Jung, H.-Y.; Kim, J. Optical sensing method for screening disease in melon seeds by using optical coherence tomography. Sensors 2011, 11, 9467-9477. [CrossRef]

19. Lee, S.-Y.; Lee, C.; Kim, J.; Jung, H.-Y. Application of optical coherence tomography to detect Cucumber green mottle mosaic virus (CGMMV) infected cucumber seed. Hortic. Environ. Biotechnol. 2012, 53, 428-433. [CrossRef]

20. Cho, N.H.; Park, K.; Wijesinghe, R.E.; Shin, Y.S.; Jung, W.; Kim, J. Development of real-time dual-display handheld and bench-top hybrid-mode SD-OCTs. Sensors 2014, 14, 2171-2181. [CrossRef]

21. Srimal, L.K.T.; Kadono, H.; Rajagopalan, U.M. Optical coherence tomography biospeckle imaging for fast monitoring varying surface responses of a plant leaf under ozone stress. In Sensing Technologies for Biomaterial, Food, and Agriculture 2013; International Society for Optics and Photonics: Bellingham, WA, USA, 2013.

22. Srimal, L.K.T.; Rajagopalan, U.M.; Kadono, H. Functional optical coherence tomography (fOCT) biospeckle imaging to investigate response of plant leaves to ultra-short term exposure of Ozone. In JSAP-OSA Joint Symposia 2014; IOP Publishing: Bristol, UK, 2015.

23. Lim, Y.; Funada, K.; Kadono, H. Monitor biological activities in seed germination by biospeckle optical coherence tomography. In Dynamics and Fluctuations in Biomedical Photonics XVI; International Society for Optics and Photonics: Bellingham, WA, USA, 2019.

24. De Silva, Y.S.K.; Rajagopalan, U.M.; Kadono, H.; Li, D. The positive and negative phenotyping of increasing Zn concentrations by Biospeckle Optical Coherence Tomography in speedy monitoring on lentil (Lens culinaris) seed germination and seedling growth. Plant Stress 2021, 2, 100041. [CrossRef]

25. Rajagopalan, U.M.; Kabir, M.; Lim, Y.; Kadono, H. Biospeckle optical coherence tomography in speedy visualizing effects of foliar application of plant growth hormone to Chinese chives leaves. BMC Res. Notes 2020, 13, 1-6. [CrossRef]

26. Aizu, Y.; Asakura, T. Bio-speckle phenomena and their application to the evaluation of blood flow. Opt. Laser Technol. 1991, 23, 205-219. [CrossRef]

27. Draijer, M.; Hondebrink, E.; Van Leeuwen, T.; Steenbergen, W. Review of laser speckle contrast techniques for visualizing tissue perfusion. Lasers Med. Sci. 2009, 24, 639-651. [CrossRef] [PubMed]

28. Szymanska-Chargot, M.; Adamiak, A.; Zdunek, A. Pre-harvest monitoring of apple fruits development with the use of biospeckle method. Sci. Hortic. 2012, 145, 23-28. [CrossRef]

29. Ramírez-Miquet, E.E.; Cabrera, H.; Grassi, H.C.; Andrades, E.D.J.; Otero, I.; Rodríguez, D.; Darias, J.G. Digital imaging information technology for biospeckle activity assessment relative to bacteria and parasites. Lasers Med. Sci. 2017, 32, 1375-1386. [CrossRef] [PubMed]

30. Alves, J.A.; Júnior, R.A.B.; Boas, E.V.d.B.V. Identification of respiration rate and water activity change in fresh-cut carrots using biospeckle laser and frequency approach. Postharvest Biol. Technol. 2013, 86, 381-386. [CrossRef]

31. Hughes, A.P.; Heath, O.V.S.; Cockshull, K.E. Leaf Area and Absolute Leaf Water Content. Ann. Bot. 1970, 34, 259-266. [CrossRef] 
32. Wang, X.; Sheng, X.; Tian, X.; Zhang, Y.; Li, Y. Organelle movement and apical accumulation of secretory vesicles in pollen tubes of Arabidopsis thaliana depend on class XI myosins. Plant J. 2020, 104, 1685-1697. [CrossRef]

33. Marcos, J. Seed vigor testing: An overview of the past, present and future perspective. Sci. Agric. 2015, 72, 363-374. [CrossRef]

34. De Silva, Y.S.K.; Rajagopalan, U.; Kadono, H. Microplastics on the growth of plants and seed germination in aquatic and terrestrial ecosystems. Glob. J. Environ. Sci. Manag. 2021, 7, 347-368. [CrossRef]

35. Mangabeira, P.A.; Ferreira, A.S.; De Almeida, A.-A.F.; Fernandes, V.F.; Lucena, E.; Souza, V.L.; Júnior, A.J.D.S.; Oliveira, A.H.; Grenier-Loustalot, M.F.; Barbier, F.; et al. Compartmentalization and ultrastructural alterations induced by chromium in aquatic macrophytes. Biometals 2011, 24, 1017-1026. [CrossRef]

36. Srivastava, R.; Chen, Y.; Deng, Y.; Brandizzi, F.; Howell, S.H. Elements proximal to and within the transmembrane domain mediate the organelle-to-organelle movement of bZIP28 under ER stress conditions. Plant J. 2012, 70, 1033-1042. [CrossRef]

37. Houston, K.; Tucker, M.; Chowdhury, J.; Shirley, N.; Little, A. The plant cell wall: A complex and dynamic structure as revealed by the responses of genes under stress conditions. Front. Plant Sci. 2016, 7, 984. [CrossRef] [PubMed]

38. Murata, M.R.; Hammes, P.S.; Zharare, G.E. Effect of solution $\mathrm{pH}$ and calcium concentration on germination and early growth of groundnut. J. Plant Nutr. 2003, 26, 1247-1262. [CrossRef]

39. Taiz, L.; Zeiger, E. Plant Physiology, 3rd ed.; Sinauer Associates Inc.: Sunderland, MA, USA, 2002.

40. Khan, R.A.; Khan, A.; Qadri, T.A. Influence of Seed Priming with FeSO4 on Germination, Growth and Biochemical Aspects of Mung bean (Vigna radiata L.) Grown Under NaCl Stress. J. Biosci. Appl. Res. 2019, 5, 519-532. [CrossRef]

41. Moatter, K. Effects of seed priming with $\mathrm{PbSO} 4$ and FeSO4 on germination and growth of seedlings of Beta vulgaris $\mathrm{L}$. under NaCl stress. Pure Appl. Biol. (PAB) 2020, 9, 1405-1423. [CrossRef]

42. Islam, A.K.M.S.; Edwards, D.G.; Asher, C.J. pH optima for crop growth. Plant Soil 1980, 54, 339-357. [CrossRef] 